\title{
Etnomatematika pada Batik Lukis Daun Singkong di Rumah Produksi Daweea Batik Bondowoso
}

\author{
Erfan Yudianto $^{1 *}$, Susanto $^{2}$, Sinta Priciliya ${ }^{3}$ \\ 1,2,3Program Studi Pendidikan Matematika, Universitas Jember \\ *erfanyudi@unej.ac.id
}

\begin{abstract}
Abstrak
Etnomatematika merupakan hubungan antara budaya dan matematika yang ditemukan dalam kebiasaan masyarakat dimana masyarakat secara tidak sadar telah menerapkan konsep matematika dalam budayanya atau kebiasaannya. Kebiasaan yang dimaksud dalam penelitian ini adalah apa saja yang dilakukan oleh pembatik dalam membuat satu lembar batik jadi setiap waktu. Tujuan dari penelitian ini adalah untuk mendeskripsikan etnomatematika pada batik tulis Daun Singkong di rumah produksi Daweea Batik Bondowoso Jawa Timur. Penelitian ini adalah penelitian kualitatif dengan pendekatan etnografi. Subjek penelitian ini adalah pengrajin di rumah produksi Batik Daweea Bondowoso. Metode pengumpulan data yang digunakan adalah observasi, wawancara dan dokumentasi. Observasi dilakukan oleh peneliti sendiri dan dibantu 2 orang observer yang sudah dibekali pedoman observasi, dan wawancara dilakukan kepada pengrajin di rumah produksi batik Daweea Bondowoso, sedangkan dokumentasi dilakukan sendiri oleh peneliti dengan menggunakan kamera recorder. Hasil pada penelitian ini menunjukkan adanya etnomatematika pada batik lukis Daun Singkong. Konsep atau unsur-unsur geometri yang ditemukan meliputi: titik, garis, sudut, bentuk bangun datar (persegi panjang, persegi), kesebangunan, kekonruenan, persamaan dan transformasi geometris (dilatasi).
\end{abstract}

Kata kunci: batik daun singkong, batik lukis, etnomatematika daun singkong

\begin{abstract}
Ethnomathematics is the relationship between culture and mathematics found in society's habits, where people have unconsciously applied mathematical concepts in their culture or habits. The custom referred to in this study is what is done by batik in making one batik sheet every time. The purpose of this study was to describe ethnomathematics on cassava leaves in the production house Daweea Batik Bondowoso East Java. This research is qualitative research with an ethnographic approach. The subject of this study was the craftsmen in the Daweea Bondowoso Batik production house. Data collection methods used are observation, interviews, and documentation. The observation was carried out by the researcher himself and assisted by two observers who were provided with observation guidelines. Interviews were conducted to artisans in Daweea Bondowoso batik production house, while the documentation was carried out by the researcher himself using a camera recorder. The results of this study indicate the existence of ethnomathematics in cassava leaves batik painting. Geometry concepts or elements found include points, lines, angles, flat shapes (rectangles, squares), congruence, concordance, equations, and geometric transformations (dilation).
\end{abstract}

Keywords: batik painting, cassava leaf batik, cassava leaf ethnomathematics

Received: March 27, 2020 / Accepted: July 1, 2020 / Published Online: July 30, 2020 


\section{Pendahuluan}

Matematika merupakan ilmu yang selalu dan terus berkembang di kehidupan manusia sampai sekarang ini. Seringkali masyarakat tidak menyadari bahwa mereka telah melibatkan matematika dalam kehiduapannya. Son (2017) menyatakan bahwa tidak hanya siswa, masyarakat juga berpikir kalau ilmu matematika tidak terkait dalam kehidupannya, padahal sebenarnya ada keterkaitan dengan kebudayaan yang ada di kehidupan masyarakat. Budaya merupakan suatu pola hidup yang diwariskan dari generasi ke generasi, dimana budaya menggambarkan ciri khas dari suatu daerah. Kekayaan alam di Indonesia sangat berlimpah dan patut untuk dibanggakan, dimana gabungan dari keduanya dikenal dengan istilah etnomatematika.

Beberapa peneliti melaporkan hasil penelitiannya terkait dengan etnomatematika antara lain Stathopoulou, Kotarinou, dan Appelbaum (2015) melaporkan hasil penelitiannya bahwa dalam belajar matematika siswa diajarkan dengan pendekatan seni peran. Irawan, Lestari, dan Rahayu (2017) mengungkapkan bahwa identifikasi etnomatematika pada batik khas Bali selain untuk pembelajaran juga berguna dalam pembuatan aplikasi untuk mendeteksi desain atau motif baru yang mungkin muncul dari hasil pengintegrasian antara keduanya. Yulianto, Prabawanto, dan Sabandar (2019) mengungkapkan bahwa pola batik Sukapura Sunda, merupakan penguatan kepada siswa-siswa terait dengan penguatan moral, sehingga siswa yakin bahwa matematika dan budaya itu tidak terpisah antara satu dengan lainnya. Sudirman, Son, dan Rosyadi (2018) mengatakan bahwa penggunaan dan pengenalan materi geometri melalui batik Paoman sangat efektif diterapkan kepada siswa sekolah dasar dikarenakan mudah untuk diidentifikasi. Abi (2016) mengatakan etnomatematika adalah ilmu matematika yang dikaitkan dengan budaya tertentu seperti kelompok pekerjaan (petani, buruh, pedagang, peternak, nelayan dan pekerjaan lainnya) baik pada kelas tinggi maupun kelas rendah. Kelima peneliti tersebut mengungkap bagaimana memanfaatkan batik sebagai hasil kolaborasi antara matematika dan budaya untuk pembelajaran di kelas.

Secara khusus batik diartikan sebagai sebuah seni menulis atau melukis pada kain, dimana dalam pengerjaannya pengrajin batik memanfaatkan lilin ("malam") dalam proses memperoleh pola atau desain di atas kain dengan menggunakan canting (Supriono, 2017). Jenis batik banyak sekali dan salah satunya adalah batik lukis, dimana dalam membuatnya digunakan cara melukis langsung pada kain yang telah dipilihnya, biasanya kain berwarna putih (Prasetyo dan Singgih, 2016). Menurut Seodjono (dalam Amrulloh dan Ratyaningrum, 2018) batik lukis ialah batik yang memiliki corak bebas dan bukan merupakan batik tradisional yang memiliki 
ikatan tertentu. Kreasi dari pewarnaan akan menghasilkan beranekaragam warna dengan pola yang kompleks. Gambar-gambar yang terdapat pada batik tulis dibuat dengan menggunakan kuas atau kombinasi antara kuas dan canting. Jika peneliti-peneliti sebelum mengangkat topik terkait pemanfaatkan etnomatematikanya saja tetapi belum menggali secara detail unsur-unsur yang bisa diambil dari batik yang diamati, maka pada artikel ini diungkap terkait unsur-unsur geometri dari objek batik yang membuat siswa lebih kritis dan kreatif lagi dalam mengembangkan batik di kabupaten Bondowoso khususnya pada batik lukis.

Bondowoso merupakan kabupaten diantara Kabupaten Jember di sebelah selatan dan Kabupaten Situbondo di bagian utara, terkenal dengan sebutan kota tape dan terdapat salah satu daerah pengrajin batik antara lain batik tulis, batik cap dan batik lukis. Batik lukis inilah salah satu yang ada di Bondowoso yaitu Batik Daun Singkong. Bondowoso sendiri dikenal sebagai Kota Tape, dimana tape berbahan dasar singkong. Oleh karena itu daun singkong dijadikan motif batik khas daerah Bondowoso. Salah satu tempat yang memproduksi batik Daun Singkong adalah rumah produksi Daweea Batik Bondowoso. Tujuan dari penelitian ini untuk mengungkapkan konsep atau unsur geometri pada batik lukis Daun Singkong.

\section{Metode}

Penelitian kualitatif dengan pendekatan etnografi memungkinkan peneliti untuk memperoleh informasi terkait kebiasaan-kebiasaan pembatik dalam memproduksi batik setiap harinya. Fokus objek yang diteliti adalah batik daun singkong yang dibuat dengan cara melukis.

Untuk memudahkan peneliti mencapai tujuan penelitian, maka langkah pertama yang dilakukan adalah pertama, pendahuluan, dimana pada langkah ini yang dilakukan adalah memilih daerah dan subjek penelitian. Dalam penelitian ini diperoleh subjek C selaku pembatik, subjek D selaku pendiri dan pemilik, dan subjek M selaku pemilik dan pembatik. Daerah penelitian di rumah produksi Daweea Batik yang berada di Kebun Karang, Pucang Anom, Jambesari Darus Sholah, Kabupaten Bondowoso, Jawa Timur. Subjek penelitian adalah pembatik di rumah produksi Daweea Batik tersebut. Langkah kedua adalah pembuatan draf instrumen yang terdiri dari pedoman observasi dan pedoman wawancara yang disusun berdasarkan hasil pengamatan di lapangan dan diwujudkan menjadi draft pedoman observasi dan wawancara. Langkah ketiga adalah validasi instrumen, yaitu memvalidasi draft instrumen pedoman observasi dan wawancara (langkah sebelumnya) kepada validator. Validator terdiri dari 2 orang yang kompeten di bidangnya yaitu dosen di bidang pendidikan dan kebudayaan. Skor validasi pedoman observasi dan wawancara dinyatakan valid dengan rincian 8,944 skala 5 untuk pedoman observasi dan 9,375 skala 5 untuk pedoman wawancara. 
Data diperoleh dengan cara melakukan observasi lokasi, wawancara ketiga subjek dan mendokumentasikan semua yang dibutuhkan dalam pengambilan data. Observasi dilakukan dengan mengamati secara langsung batik Daun Singkong yang terdapat di rumah produksi Daweea Batik dan proses pembuatan batik Daun Singkong tersebut. Disertakan pula dokumentasi saat proses pembuatan desain batik. Wawancara dilakukan kepada pembatik di rumah produksi Daweea Batik Bondowoso untuk memperoleh data atau informasi sebanyak dan sejelas mungkin. Langkah berikutnya adalah analisis data, langkah ini dilakukan dengan menyusun data sesuai dengan fokus kajian masalah dan tujuan penelitian. Langkah terakhir adalah kesimpulan, dimana peneliti mendapatkan hasil akhir dari penelitiannya dan menjawab sesuai dengan tujuan penelitian. Pengkodean pada langkah wawancara dibagi menjadi dua yaitu peneliti dan subjek penelitian dengan ketentuan dua angka pertama menyatakan menit dan dua angka terakhir menyatakan detik seperti kode PBL00:50 mengartikan bahwa peneliti mengajukan pertanyaan pada detik ke 00:50 dan kode MBL01:31 mengartikan bahwa subjek menjawab pada waktu menit ke 01 detik ke 31.

\section{Hasil Penelitian}

Pada proses pembuatan pola/desain pada batik lukis Daun Singkong terdapat unsur atau konsep geometri yang secara tidak sadar diterapkan oleh para pembatik. Unsur atau konsep geometri yang digunakan meliputi: titik, garis, sudut, bangun datar, kesebangunan dan transformasi geometri.

\section{Unsur Titik pada Batik Lukis Daun Singkong}

Titik tidak dapat didefinisikan namun dapat ditentukan letaknya dan berdimensi nol. Batik sendiri merupakan kegiatan membuat titik menggunakan canting dan malam. Pada penelitian ini, etnomatematika muncul saat pembatik membuat titik pada desain batik. Menurut pembatik, pola titik-titik didapatkan dari hasil menorehkan malam menggunakan canting pada kain. Titik digambar begitu saja tanpa memikirkan jumlahnya dan ukuran titik beragam. Berikut pada ga,bar 2 merupakan kutipan wawancara terkait pola titik.
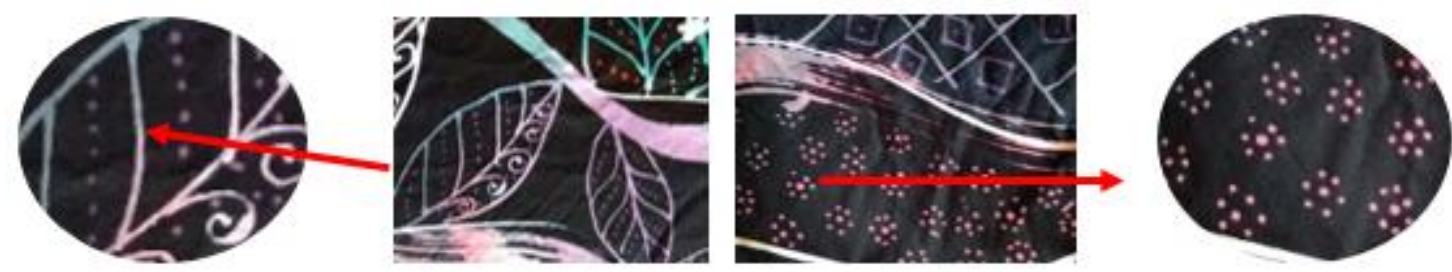

Gambar 1. Pola Titik pada Batik Tulis Daun Singkong

PBL00:50 Ini kayak titik-titik, tulang daunnya bikinnya pake canting apa kuas mas? 
MBL00:55 : Pake canting (terdiam cukup lama), kalau yang gores-goresan itu pake kuas

PBL01:28 : Kalau titik-titik gini, ini termasuk isen atau bukan?

MBL01:31 : Iya, isen

PBL01:40 : Berarti titik-titik disetiap daun ini ndak sama jumlahnya ya?

MBL01:43 : Iya

\section{Unsur Garis pada Batik Lukis Daun Singkong}

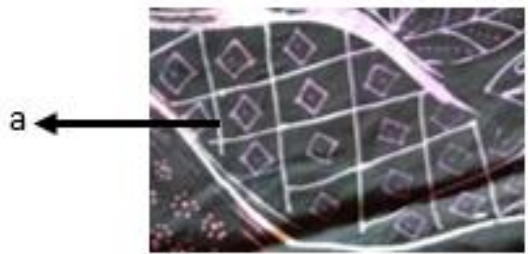

(a)

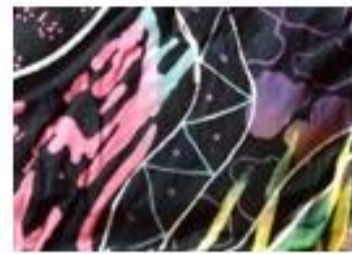

(b)

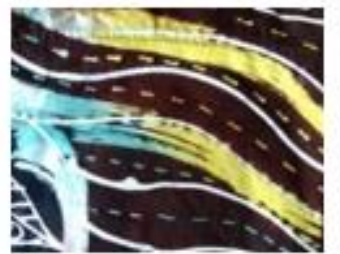

(c)

Gambar 2. Pola Garis pada Batik Lukis Daun Singkong

Pada penelitian ini, etnomatematika muncul saat pembatik membuat garis pada desain batik. Untuk membuat garis pembatik tidak perlu menggunakan penggaris, namun langsung menorehkan malam menggunakan canting tanpa perlu diukur panjang dan jaraknya. Saat menggambar garis tersebut diusahakan lurus, namun karena menggambarnya langsung menggunakan tangan atau manual akhirnya garis tersebut tidak terlihat lurus. Berikut kutipan wawancara terkait pola garis.

PBL02:23 : Kalau yang ini (a pada Gambar 2(a)), pakai penggaris atau ndak buatnya?

MBL02:28 : Ndak. Ndak pake penggaris, cuma kita usahakan lurus gitu aja

PBL02:33 : Terus, untuk jaraknya itu ndak sama mas?

MBL02:35 : Iya

\section{Unsur Sudut pada Batik Lukis Daun Singkong}
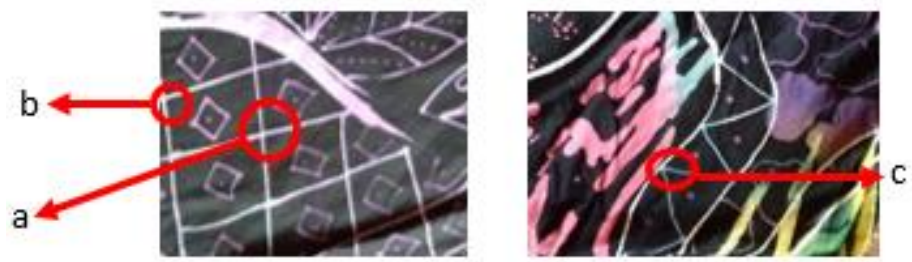

Gambar 3. Ilustrasi Pola Sudut pada Batik Lukis Daun Singkong

Pada penelitian ini, etnomatematika muncul saat pembatik membuat pola sudut pada desain batik. Berdasarkan hasil penelitian pembatik secara tidak sadar melakukan aktivitas matematika yaitu dalam membuat pola sudut. Pada batik lukis Daun Singkong terdapat konsep sudut yaitu dua garis yang bertemu pada satu titik pangkal yang sama. Terlihat pada Gambar 3, ornamen yang dibuat memiliki titik pangkal yang sama. Sudut yang dihasilkan dari kedua garis tersebut adalah sudut siku-siku (ukuran 90 ) yang ditunjuk panah (b) dan sudut lancip (ukuran $<90^{\circ}$ ) yang ditunjuk panah (a) dan (c). Berikut kutipan wawancara terkait pola sudut. 


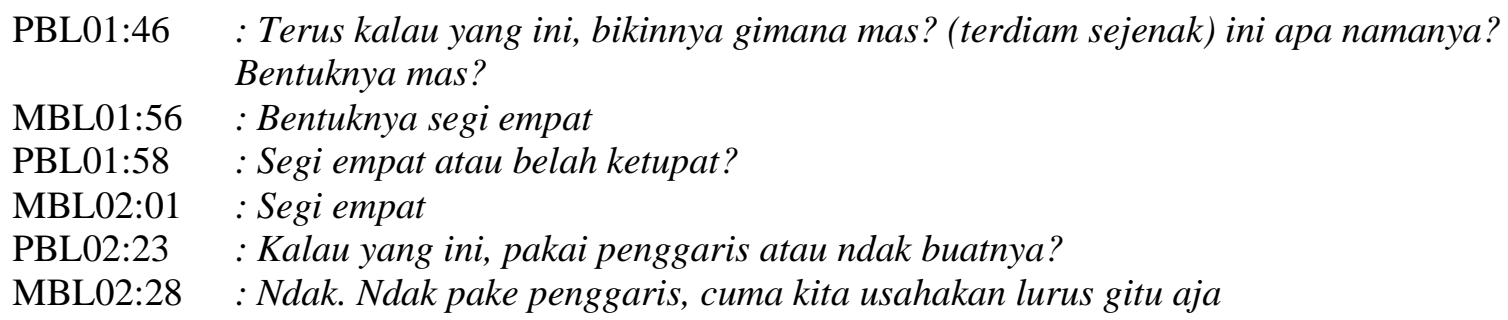

\section{Unsur Bangun Datar pada Batik Lukis Daun Singkong}

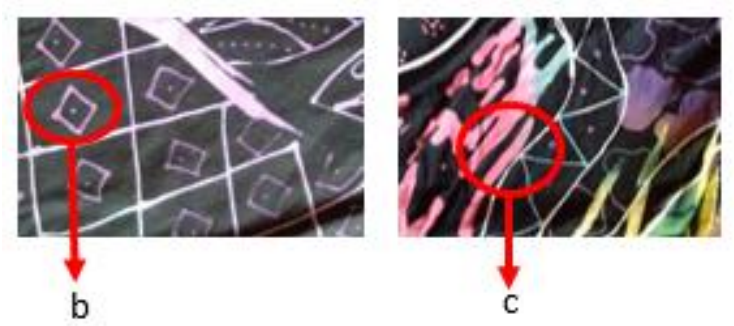

Gambar 4. Ilustrasi Pola Bangun Datar pada Batik Lukis Daun Singkong

Pada penelitian ini, etnomatematika muncul saat pembatik membuat pola bangun datar pada desain batik. Berdasarkan hasil penelitian pada batik lukis Daun Singkong, terdapat bangun datar yang digambar yaitu segi empat. Untuk membuat bangun datar tersebut, pembatik hanya langsung menggambar diatas kain. Pembatik mengatakan bahwa gambar yang ditunjuk arah panah (b) pada Gambar 4 adalah segi empat dan gambar yang ditunjuk arah panah (c) pada Gambar 4 bukan segitiga. Pertanyaan tersebut dapat dilihat pada kutipan wawancara berikut.

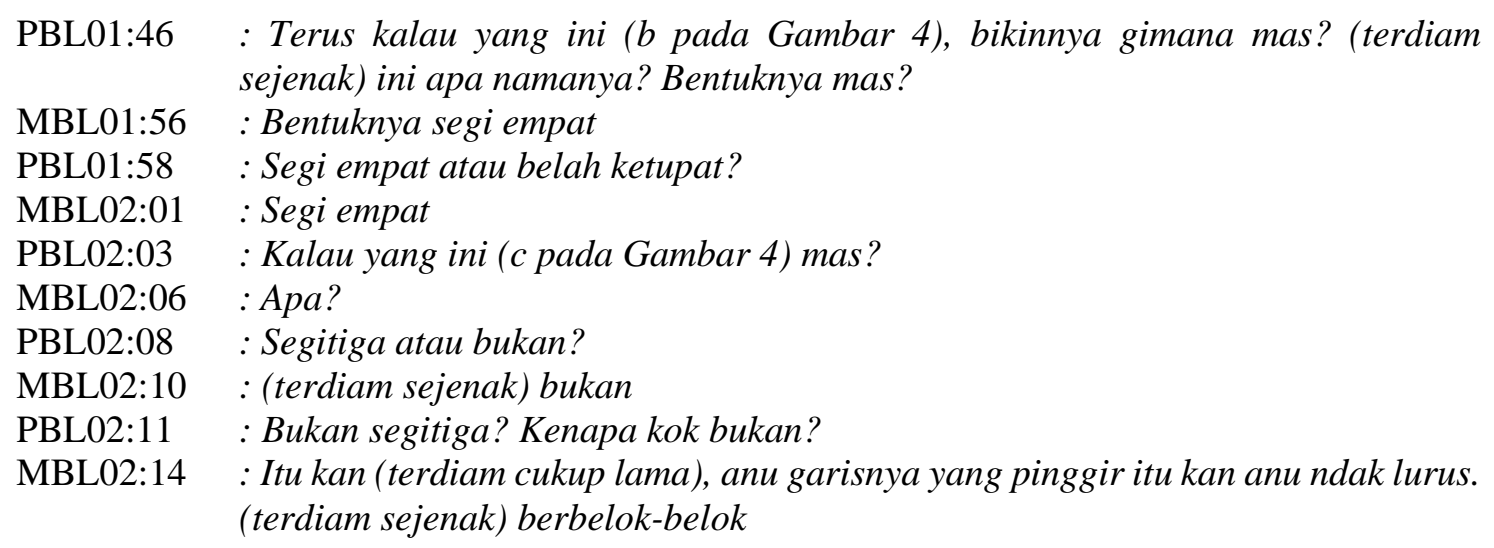




\section{Unsur Kesebangunan pada Batik Lukis Daun Singkong}

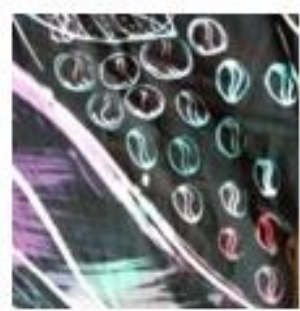

(a)

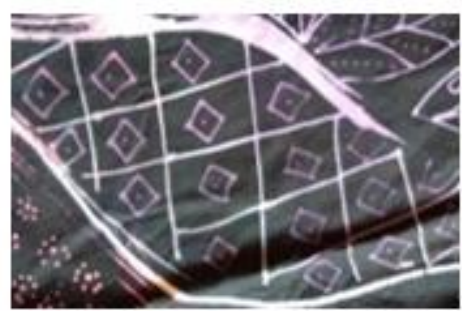

(b)

Gambar 5. Pola Kesebangunan pada Batik Lukis Daun Singkong

Pada penelitian ini, etnomatematika muncul saat pembatik membuat pola/desain dan hasil batik lukis Daun Singkong. Berdasarkan hasil penelitian, pembatik secara tidak sadar melakukan aktivitas matematika yaitu dalam membuat pola ornamen. Ornamen batik yang memiliki bentuk sama namun ukurannya sebanding merupakan ornamen yang sebangun. Konsep kesebangunan dapat dilihat pada ornamen biji kopi dan segi empat. Pada ornamenornamen tersebut tampak satu ornamen memiliki bentuk yang sama dengan ornamen lainnya. Namun ukurannya berbeda, ada yang diperbesar, ada yang diperkecil, dan ada yang sebanding atau mirip. Menurut pembatik ornamen tersebut langsung digambar tanpa pola dan sengaja dibentuk besar kecil agar terlihat indah. Berikut kutipan wawancara terkait pola kesebangunan.

PBL01:12 : Ini besarnya biji kopi, ada yang besar ada yang kecil itu sengaja dibuat seperti itu atau gimana mas?

MBL01:20 : Ya, mengalir aja. Kan tanpa pola, jadinya ya (terdiam sejenak) bisa dibilang agak ngawur lah

Berdasarkan hasil observasi dan wawancara diperoleh bahwa dalam pembuatan desain batik lukis Daun Singkong hanya terdapat konsep kesebangunan. Konsep kekongruenan tidak digunakan karena jenis batik ini merupakan batik yang dibuat tanpa pola sehingga ukuran dari setiap ornamen tidak sama.

\section{Unsur Transformasi Geometri pada Batik Lukis Daun Singkong}
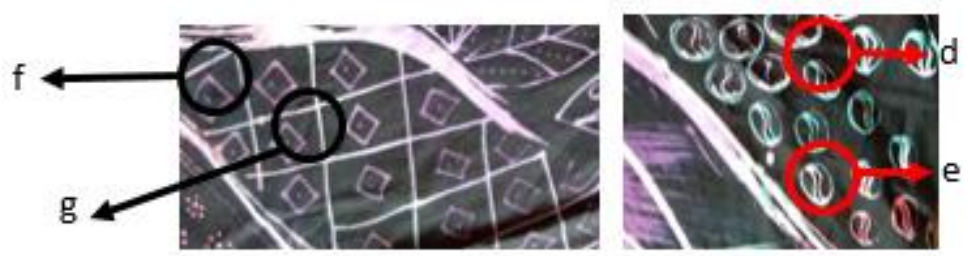

Gambar 6. Pola Dilatasi pada Batik Lukis Daun Singkong

Konsep transformasi geometri yang terdapat pada batik lukis Daun Singkong adalah dilatasi. Pada dasarnya konsep dilatasi sama seperti kosep kesebangunan. Dimana jika suatu 
bangun dikatakan sebangun maka bangun tersebut juga dikatakan mengalami dilatasi baik itu perbesaran maupun pengecilan. Berdasarkan hasil penelitian dapat diketahui bahwa etnomatematika muncul saat pembatik membuat pola/desain batik dimana didalamnya terdapat konsep dilatasi. Konsep dilatasi tampak pada ornamen yang sebangun yakni pada ornamen kopi yang ditunjuk panah (d) dan (e) serta pada segi empat yang ditunjuk panah (f) dan (g) pada Gambar 6. Dalam membuat ornamen tersebut pembatik tidak memeperhatikan, hanya mengirangira saja dan jika dirasa bentuknya kurang sesuai maka disesuaikan. Berikut kutipan wawancara terkait pola dilatasi.

PBL01:12 : Ini besarnya biji kopi, ada yang besar ada yang kecil itu sengaja dibuat seperti itu atau gimana mas?

MBL01:20 : Ya, mengalir aja. Kan tanpa pola, jadinya ya (terdiam sejenak) bisa dibilang agak ngawur lah

\section{Pembahasan}

Pada penelitian ini etnomatematika yang muncul atau terlihat adalah unsur-unsur geometri antara lain: titik, garis, sudut, bangun datar (segi empat), kesebangunan dan transformasi geometri (dilatasi) (Aprillianti, Sunardi, \& Yudianto, 2019; Stathopoulou, Kotarinou, Appelbaum, 2015; Wahyu, Setiawan, \& Sunardi, 2018). Pada Gambar 1 terlihat pola titik pada batik tulis daun singkong dan dikonfirmasi melalui cuplikan wawancara. Cara pembuatannya dilakukan menurut apa yang subjek biasa kerjakan. Sejalan dengan Stathopoulou, Kotarinou, dan Appelbaum (2015) yang juga menghasilkan konsep titik. Pada gambar 2, pola garis pada batik lukis daun singkong juga muncul pada hasil penelitian Wahyu et al. (2018). Astuti, Purwoko, \& Sintiya (2019) menghasilkan pola bilangan khususnya Aritmetika dan jika dihubungkan akan menghasilkan pola-pola sebagai berikut.

\section{Pola titik}

Pada penelitian ini, etnomatematika muncul saat pembatik membuat titik pada desain batik. Titik tidak dapat didefinisikan namun dapat ditentukan letaknya dan berdimensi nol. Batik sendiri merupakan kegiatan membuat titik menggunakan canting dan malam. Menurut $\mathrm{C}$ titik merupakan bagian dari isen dan dibuat untuk memperindah motif yang ada. Titik digambar menggunakan canting nomor 1 atau canting isen. Cara pembatik membuat titik adalah dengan memanaskan malam terlebih dahulu di atas wajan kemudian canting diisi dengan malam dan menorehkan canting tersebut pada kain. Malam tidak boleh terlalu panas ataupun terlalu dingin, karena jika terlalu panas maka saat menorehkannya pada kain akan "mblobor". 


\section{Pola garis}

Pada penelitian ini, etnomatematika muncul saat pembatik membuat garis pada desain batik. Garis merupakan himpunan dari titik-titik yang tak hingga. Jika ada dua titik pada garis, selalu ada titik yang terletak diantara dua titik tersebut. Cara pembatik membuat garis ada bermacam-macam, yaitu dengan menggunakan penggaris dan langsung menggunakan canting. Menurut D ada garis yang termasuk isen, garis tersebut dibuat untuk memperindah desain motif yang ada. Selain itu menurut $M$ ada garis yang perlu digambar menggunakan penggaris agar lurus dan rapi. Ada pula garis yang saat dipola lurus kemudian setelah dicanting garis tersebut menjadi tidak lurus. Karena proses pencantingan tidak menggunakan penggaris. Untuk garis yang merupakan isen pembatik tidak perlu membuat pola, hanya saja langsung menorehkan malam pada kain. Serta jumlah garis tersebut tidak menentu dan tidak sama pada setiap ornamennya.

\section{Pola sudut}

Menurut Alexander dan Koeberlein (2011) suatu sudut terbentuk dari pertemuan dua sinar yang memiliki titik pangkal yang sama. Sebuah sudut yang berukuran kurang dari $90^{\circ}$ disebut sudut lancip. Sudut yang memiliki ukuran tepat $90^{\circ}$ disebut sudut siku-siku. Jika ukuran sudut diantara $90^{\circ}$ dan $180^{\circ}$, maka sudut tersebut dinamakan sudut tumpul. Sudut yang memiliki ukuran tepat $180^{\circ}$ disebut sudut berpelurus. Sudut yang memiliki ukuran antara $180^{\circ}$ dan $360^{\circ}$ disebut sudut refleks. Pada penelitian ini, etnomatematika muncul saat pembatik membuat pola sudut pada desain batik. Berdasarkan hasil penelitian pada batik Daun Singkong, D dan M selaku pembatik secara tidak sadar melakukan aktivitas matematika yaitu dalam membuat pola sudut.

\section{Pola Bangun Datar}

Bangun datar yang sering dijumpai dalam pembelajaran di sekolah antara lain segitiga, segi empat dan lingkaran. Pada penelitian ini, etnomatematika muncul saat pembatik membuat pola bangun datar pada desain batik. Berdasarkan hasil penelitian pada hasil batik lukis Daun Singkong, terdapat segi empat dan lingkaran. Segi empat yang dimaksud adalah persegi panjang dan belah ketupat. Menurut Alexander dan Koeberlein (2011) persegi panjang adalah jajar genjang dengan satu sudut siku-siku dan belah ketupat adalah jajar genjang dengan dua sisi yang berdekatan kongruen. Pengertian jajar genjang sendiri adalah segi empat dengan dua pasang sisi yang berhadapan sejajar dan sama panjang. D menyebut belah ketupat sebagai “wajik", lingkaran sebagai bulat-bulat dan persegi panjang sebagai kotak. M menyebut belah 
ketupat sebagai segi empat. Untuk membuat bangun datar tersebut pembatik tidak mengukur panjang setiap sisinya, hanya langsung menggambar diatas kain. Namun untuk membuat persegi panjang, pembatik menggunakan penggaris agar lurus dan rapi. Hal ini juga terlihat dari hasil penelitian Putri (2017) yang mengatakan bahwa hasil dari objek-objek yang diamati dengan baik dapat digunakan sebagai sumber dari objek tersebut seperti menghasilkan konsep geometri bangun datar. Selanjutnya Khofifah, Sugiarti, dan Setiawan (2018) juga melaporkan hasil penelitian terkait batik Banyuwangi menghasilkan objek-objek bangun datar yang dikembangkan lagi menjadi lembar kerja siswa.

\section{Pola Kesebangunan}

Apabila dua bangun geometri memiliki bentuk yang sama maka dua bangun tersebut dikatakan sebangun. Apabila dua bangun memiliki bentuk yang sama dan semua sisi dan sudut yang bersesuaian memiliki ukuran yang sama, maka kedua bangun tersebut dikatakan kongruen (Alexander \& Koeberlein, 2014). Pada penelitian ini, etnomatematika muncul saat pembatik membuat pola ornamen yang memiliki bentuk dan ukuran yang sama pada desain batik. Berdasarkan hasil penelitian pada D dan M selaku pembatik secara tidak sadar melakukan aktivitas matematika yaitu dalam membuat pola ornamen yang memiliki bentuk dan ukuran yang sama. Ornamen batik yang memiliki bentuk sama namun ukurannya sebanding merupakan ornamen yang sebangun. Ornamen batik yang memiliki bentuk dan ukuran sama merupakan ornamen yang kongruen. Sejalan dengan Nurjamil dan Nurhayati (2019) yang melaporkan bahwa batik tulis khas Tasikmalaya juga menghasilkan pola-pola matematika yang membentuk bangun datar yang sebangun termasuk di dalamnya berhubungan dengan konsep pencerminan atau refleksi. Selanjutnya hasil penelitian Sudirman, Rosyadi, dan Lestari (2017) melaporkan bahwa unsur transformasi geometri juga diperoleh dalam penelitian terkait batik Indramayu yaitu translasi dan refleksi. Diperkuat dengan hasil penelitian Yanti \& Haji (2019) tentang kain Besurek Bengkulu yang menghasilkan unsur transformasi lengkap yaitu translasi, refleksi, rotasi dan dilatasi.

\section{Simpulan}

Terdapat etnomatematika pada batik lukis Daun Singkong di rumah produksi Daweea Batik Bondowoso. Batik Daun Singkong khas Bondowoso memiliki karakteristik yaitu bentuk satu helai daun singkong terdiri dari tujuh jari daun. Etnomatematika muncul saat pembatik membuat pola/desain dan pada batik lukis Daun Singkong terdapat unsur atau konsep geometri. 
Unsur atau konsep geometri yang terdapat pada batik lukis Daun Singkong yakni titik, garis, sudut, bangun datar (segi empat), kesebangunan dan transformasi geometri (dilatasi). Untuk membuat unsur atau konsep geometri tersebut pembatik menggunakan cara pengukuran atau cara perkiraan.

\section{Referensi}

Abi, A. M. (2016). Integrasi etnomatematika dalam kurikulum matematika sekolah. Jurnal Pendidikan Matematika Indonesia, 1(1), 1-6. https://doi.org/10.26737/jpmi.v1i1.75.

Alexander, D. C., \& Koeberlein, G. M. (2011). Elementary geometry for college students. Canada: Cengage Learning.

Alexander, D. C., \& Koeberlein, G. M. (2014). Elementary geometry for college students (Fifth Edit; S. Williams, ed.). Belmont USA: United States Copyright.

Amrulloh, R. N. F., \& Ratyaningrum, F. (2018). Batik lukis karya guntur sasono di Desa Carat Kecamatan Kauman Kabupaten Ponorogo periode 2008-2016. Jurnal Seni Rupa, 6(1), 653-662.

Aprillianti, I., Sunardi, \& Yudianto, E. (2019). Etnomatematika pada aktivitas petani kakao desa temuasri sempu banyuwangi sebagai bahan ajar siswa. Saintifika, 21(1), 1-8.

Astuti, E. P., Purwoko, R. Y., \& Sintiya, M. W. (2019). Bentuk etnomatematika pada Batik Adipurwo dalam pembelajaran pola bilangan. Journal of Mathematics Science and Education, 1(2), 1-16. https://doi.org/10.31540/jmse.v1i2.273.

Irawan, A., Lestari, M., \& Rahayu, W. (2017). Pendekatan unsur etnomatematika dalam pengenalan motif batik khas Bali. Seminar Nasional Matematika dan Pendidikan Matematika, 2(1), 34-39.

Khofifah, L., Sugiarti, T., \& Setiawan, T. B. (2018). Etnomatematika karya seni batik khas Suku Osing Banyuwangi sebagai bahan lembar kerja siswa materi geometri transformasi. Kadikma, 9(3), 148-159.

Mauluah, L., \& Marsigit. (2019). Ethnomathematics for elementary student: Exploration the learning resources at kraton Yogyakarta. International Journal of Scientific and Technology Research, 8(7), 776-780.

Nurjamil, D., \& Nurhayati, E. (2019). Eksplorasi unsur matematika dalam pembuatan batik khas Tasikmalaya. Jurnal Matematika Ilmiah STKIP Muhammadiyah Kuningan, 5(2), 111-119. https://doi.org/10.33222/jumlahku.v5i1.530.

Prasetyo, A., \& Singgih. (2016). Karakteristik motif batik Kendal interpretasi dari wilayah dan letak geografis. Imajinasi: Jurnal Seni, 10(1), 51-60.

Putri, L. I. (2017). Etnomatematika, kesenian tradisional rebana, pembelajaran matematika. Jurnal Ilmiah Pendidikan Dasar, IV(1), 21-31.

Son, A. L. (2017). Study ethnomatematics: pengungkapan konsep matematika dan karakter siswa pada permainan kelereng masyarakat suku Dawan. Journal of Medives, 1(2), 100110.

Stathopoulou, C., Kotarinou, P., \& Appelbaum, P. (2015). Ethnomathematical research and drama in education techniques: developing a dialogue in a geometry class of 10th grade students. Revista Latinoamericana de Etnomatemática, 8(2), 105-135.

Sudirman, Rosyadi, \& Lestari, W. D. (2017). Penggunaan etnomatematika pada karya seni batik Indramayu dalam pembelajaran geometri transformasi. Pedagogy, 2(1), 74-85. https://doi.org/10.30738/indomath.v1i1.2093.

Sudirman, S., Son, A. L., \& Rosyadi, R. (2018). Penggunaan etnomatematika pada batik Paoman dalam pembelajaran geomteri bidang di sekolah dasar. IndoMath: Indonesia 
Mathematics Education, 1(1), 27. https://doi.org/10.30738/indomath.v1i1.2093.

Sunardi, Setiawan, T. B., Yudianto, E., Sugiarti, T., Ambarwati, R., \& Agustin, M. A. (2019). Ethnomathematics activities of coffee farmers in Sidomulyo Jember area as project student sheet. Journal of Physics: Conference Series, 1321(2). https://doi.org/10.1088/17426596/1321/2/022124.

Supriono, Y. P. (2017). The heritage of batik identitas Pemersatu kebanggaan bangsa (1st ed.; Maya, ed.). Yogyakarta: ANDI.

Wahyu, S., Setiawan, T. B., \& Sunardi. (2018). Etnomatematika pada Pura Mandara Giri Semeru Agung sebagai bahan pembelajaran matematika. KadikMa, 9(1), 156-164.

Yanti, D., \& Haji, S. (2019). Studi tentang konsep-konsep transformasi geometri pada kain Besurek Bengkulu. JNPM (Jurnal Nasional Pendidikan Matematika), 3(2), 265. https://doi.org/10.33603/jnpm.v3i2.1744.

Yulianto, E., Prabawanto, S., \& Sabandar, J. (2019). Pola matematis dan sejarah batik sukapura: Sebuah kajian semiotika. Jurnal Penelitian Pendidikan Dan Pengajaran Matematika, 4(1), 15-30. 